\title{
The corrosion resistance and mechanism of AT13/Fe-based amorphous
}

\section{composite coatings}

Zhenhua $\mathrm{Chu}^{1 *}$, Shikun Teng ${ }^{1}, \quad$ Yuyun Zhou ${ }^{1}, \quad$ Xingwei Zheng ${ }^{2 * *}, \quad$ Jingxiang $\mathrm{Xu}^{1}$, Fang Wang ${ }^{1}$, Baosen Zhang $^{3}$

1. Department of Mechanical Engineering, College of Engineering, Shanghai Ocean University, Shanghai, 201306, China

2. College of Science, Donghua University, shanghai, 201620, China

3. School of Materials Science and Technology, Nanjing Institute of Technology, Nanjing, 211167, China

* Corresponding author:

Zhenhua Chu E-mail zhchu@shou.edu.cn Tel: +86-22-60204810; Fax: +86-2226564810

** Corresponding author:

Xingwei Zheng; E-mail zhengxingwei@,dhu.edu.cn; Tel: +86-21-61900818; Fax:

$+86-21-61900$ 
Abstract: In the present study, the corrosion resistance of amorphous coating and composite coatings in 3.5 wt. $\% \mathrm{NaCl}, 0.5 \mathrm{M} \mathrm{H}_{2} \mathrm{SO}_{4}$ and $10 \mathrm{wt} . \% \mathrm{NaOH}$ solution were studied. The composite coatings exhibit superior corrosion resistance. When the content of AT13 $\left(\mathrm{Al}_{2} \mathrm{O}_{3}-13\right.$ wt.\% $\left.\mathrm{TiO}_{2}\right)$ was 15 wt.\%, the composite coating has the lowest corrosion current density $\left(1.75 \times 10^{-6} \mathrm{~A} \mathrm{~cm}^{-2}\right)$, which is $5.14 \times 10^{-5} \mathrm{~A} \mathrm{~cm}^{-2}$ for Fe-based metallic glassy coating, and the highest corrosion potential $(-411 \mathrm{mV})$, which is -580 $\mathrm{mV}$ for Fe-based metallic glassy coating. The breakdown potential of the passivation film in 3.5 wt.\% $\mathrm{NaCl}$ solution was much higher than that of 316L.The long-time immersion corrosion tests carried out on different coatings showed that the corrosion protection effect of coating was enhanced with the increase of the amount of AT13 added.

Keywords: Fe-based amorphous coating; AT13; Plasma spraying; Corrosion resistance 


\section{Introduction}

2 Although bulk metallic glasses (BMGs) exhibit ultrahigh hardness and strength,

3 superior corrosion resistance and wear resistance ${ }^{[1-4]}$, metallic glasses are seldom used

4 in engineering, because of the limitation of the glassy formation ability. Fortunately, the

5 metallic glassy coating can be fabricated by spraying method ${ }^{[5]}$. It is just need to put

6 micron powders together then it can enlarge its size at 3-dimension. However, due to

7 the deformation mechanism of bulk metallic glasses, which depends on the

8 development of shear bands, it exhibits poor plastic deformation. As a result, a great

9 amount of research efforts have been devoted to fabricate bulk metallic glassy

10 composites (BMGCs) to improve the plasticity of BMGs by introducing ductile

11 metallic crystalline or ceramic phases with high strength into the metallic glassy matrix

12 in order to form multiple shear bands.

13 It is reported ${ }^{[6]}$ that the amorphous composite coatings can improve the bonding and 14 impact resistance of the coatings. Wang et al. ${ }^{[7]}$ found that the WC phase-reinforced

15 Fe-based amorphous coating is unstable in alkaline environment and then chemically

16 reacts to dissolve, diminishing the corrosion resistance. Cai et al. ${ }^{[8]}$ improved the wear

17 resistance of the coating via enhancing the bonding strength between the ceramic

18 particles and the matrix. In our previous studies ${ }^{[9-11]}$, the excellent wear resistance and

19 corrosion resistance were obtained in composite coatings. Electrochemical corrosion

20 studies were made to further investigate the effect of the AT13(Al2O3-13 wt.\% TiO2)

21 ceramic phase on the fabricated materials in different aggressive media and the long-

22 term corrosion mechanism. In the previous study ${ }^{[12]}, \mathrm{ZrO}_{2}$ ceramic powders were added 
into the Fe-based metallic glassy coating by gas multiple-tunnel, due to high melting temperature of $\mathrm{ZrO}_{2}$. In this study, AT13 ceramic was adopted, due to lower melting temperature, to fabricate composite Fe-based metallic glassy composite coating by mixing Fe-based metallic powders and AT13 ceramic powders as feedback powders. It is an easy method to obtain composite coatings. And it is worthy to note that the ability of formation of amorphous isn't affected by addition of AT13.

In this paper, the coating corrosion resistance in different medium and the effect of the second phase content on the electrochemical corrosion performance of the coatings were studied. Moreover, the long-term corrosion behavior of amorphous composite coating was evaluated in $\mathrm{NaCl}$ solution. It is observed that when the content of AT13 was $15 \mathrm{wt} . \%$, the coating composite has the lowest corrosion current density and the highest corrosion potential.

\section{Experimental procedure}

$\mathrm{Fe}_{54} \mathrm{Cr}_{25} \mathrm{Mo}_{17} \mathrm{C}_{2} \mathrm{~B}_{2}$ alloy amorphous powders were produced by high pressure Ar gas atomized. Then different weight fractions (5-20\%) of $\mathrm{Al}_{2} \mathrm{O}_{3}-13 \% \mathrm{TiO}_{2}(\mathrm{AT} 13)$ ceramic powders $(20-40 \mu \mathrm{m})$ were mixed with amorphous powders in a mechanical mixing machine for 4 hours. The mild steel $(0.45$ wt. $\%$ C) was selected as substrate with a size of $10 \mathrm{~mm} \times 10 \mathrm{~mm} \times 12 \mathrm{~mm}$. All substrates were machined and polished, then degreased by acetone, dried in air and grit-blasted prior the deposition. The coating was fabricated by plasma spraying process.

The microstructures of powders and as-sprayed coating were examined by scanning electron microscopy (SEM, S4800) coupled with energy dispersive spectroscopy (EDS) 
and X-ray diffraction (XRD, Bruker D8 Focus).

Electrochemical measurements were performed at room temperature in a threeelectrode cell, therefore utilized the saturated calomel electrode (SCE) and the graphite electrode as the reference and auxiliary electrode, respectively. Specimens for the corrosion test were closely sealed with epoxy resin, leaving only an end-surface with a surface area of $1 * 1 \mathrm{~cm}^{2}$ exposed for testing. The electrochemical behavior was characterized by recording a Tafel plot at a potential sweep rate of $0.5 \mathrm{mVs}^{-1}$ from -100 $\mathrm{mV}$ to $1500 \mathrm{mV}$ in $3.5 \mathrm{wt} . \% \mathrm{NaCl}, 0.5 \mathrm{M} \mathrm{H}_{2} \mathrm{SO}_{4}$ and $10 \mathrm{wt} . \% \mathrm{NaOH}$ solution open to air after immersing the specimens for an hour. Each test was repeated three times for repeatability and reliability. In addition, electrochemical impedance spectroscopy (EIS) was examined at OCP in $3.5 \mathrm{wt} . \% \mathrm{NaCl}$ solution with sinusoidal amplitude of $10 \mathrm{mV}$ in the frequency ranging from $10^{5} \mathrm{~Hz}$ to $0.01 \mathrm{~Hz}$. The impedance plots were interpreted on the basic of the equivalent circuit using a suitable fitting procedure by Echem Analyst. After EIS measurement, the corroded surface was examined by SEM.

For composition analysis in passivation film formed after electrochemical treatment, a specimen was potentiodynamically polarized into the middle of the passive region and then take out immediately for X-ray photoelectron spectroscopy.

\section{Results}

3.1 Characterization of powders and as-sprayed coatings

The XRD spectra of mixed powders and amorphous composite coatings is shown in Fig. 1. It can be seen that the mixed powders mainly contain Fe-based amorphous phase, $\alpha-\mathrm{Al}_{2} \mathrm{O}_{3}$ phase and $\mathrm{A}-\mathrm{TiO}_{2}$ phase. With the increase of AT13 powder, the crystal peak of $\alpha-\mathrm{Al}_{2} \mathrm{O}_{3}$ becomes more obvious, and the intensity value gradually increases. By 
comparison, it is found that the $\mathrm{Al}_{2} \mathrm{TiO}_{5}$ crystal peak is observed more clearly when the AT13 content in the composite powder increased to $20 \%$ (Fig.1(a)). As is shown in Fig. 1(b), broad diffraction bump is appeared at the angle of $2 \theta=43^{\circ} \sim 45^{\circ}$ of all coatings.

Moreover, the crystal peak corresponding to the $\gamma-\mathrm{Al}_{2} \mathrm{O}_{3}$ phase also appeared in the spectrum of the composite coatings, and the intensity of the diffraction peak increased with the increase of the content of the added content.

(a)

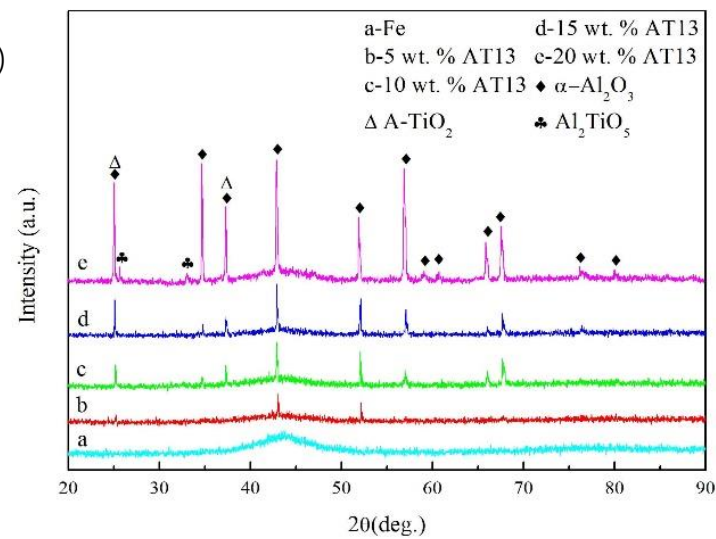

(b)

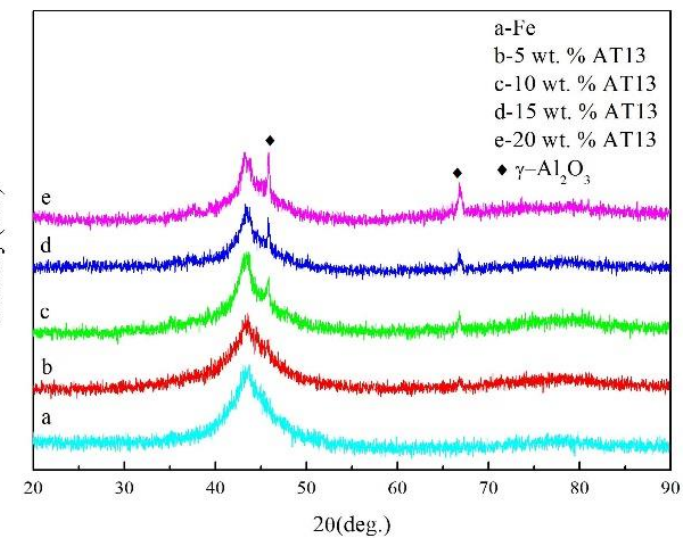

Fig. 1 (a) The XRD Spectra: (a) mixed powders; (b) amorphous composite coatings

The surface morphology and structure of the cross-section of Fe-based amorphous coating are shown in Fig. 2. It is found that as-sprayed coating is closely bonded to substrate without obvious cracks. The amorphous coating exhibits a relatively uniform and dense structure with a thickness of about $250 \mu \mathrm{m}$. In addition, the porosity of the coating is about $4.305 \%$.
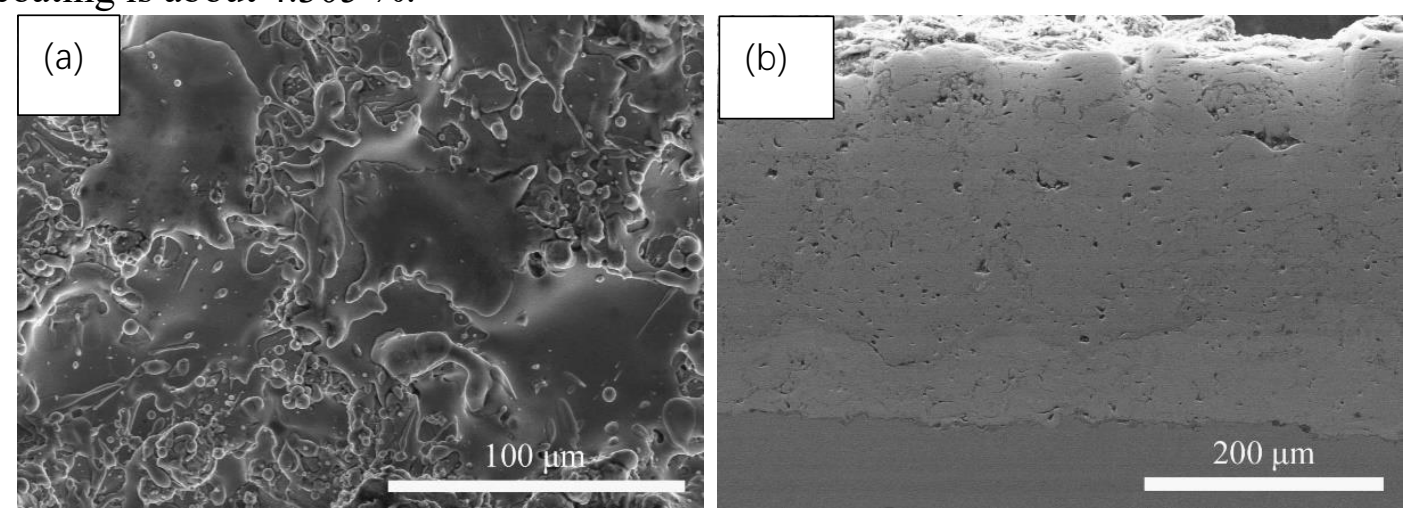
Fig. 2 SEM images of (a) as-sprayed surface and (b) cross-section of amorphous coating

\subsection{Corrosion resistance measurements}

\subsubsection{Potentiodynamic polarization test}

Fig. 3 displays the potendiodynamic polarization curves of different samples in different corrosive solutions. Table 1 shows some electrochemical parameters, such as corrosion potential ( $\left.\mathrm{E}_{\mathrm{corr}}\right)$, corrosion current density ( $\left.\mathrm{i}_{\text {corr }}\right)$, transpassive current density $\left(\mathrm{i}_{\text {pass }}\right)$, transpassive potential $\left(\mathrm{E}_{\mathrm{tr}}\right)$ and corrosion rate. In $3.5 \mathrm{wt} . \% \mathrm{NaCl}$ solution (Fig. 3(a)), the amorphous coating and composite coatings present excellent corrosion resistance, and the self-corrosion potential is from $-580 \mathrm{mV}$ to $-411 \mathrm{mV}$. Corrosion current density on the order of $10^{-5} \mathrm{Acm}^{2} \sim 10^{-6} \mathrm{Acm}^{2}$. The transpassive potential is up to $1.0 \mathrm{~V}_{\mathrm{SCE}}$ and passivation region is more than $1.0 \mathrm{~V}_{\mathrm{SCE}}$. It reflected that there is an effective passivation film on the surface, which can maintain stability in a wide range and protect the matrix from corrosion. Moreover, with the addition of the AT13 ceramic phase, the self-corrosion potential of the composite coatings was all positively shifted compared with the pure Fe-based coating. The transpassive potential of 15 wt.\% AT13 composite coating was up to $1.2 \mathrm{~V}_{\mathrm{SCE}}$, implying that the corrosion resistance of composite coating is superior to the single amorphous coating. Comparing the selfpotential of $316 \mathrm{~L}$ stainless steels with coatings, it was found that composite coating has the best electrochemical parameters and the best corrosion resistance in a 3.5 wt.\% $\mathrm{NaCl}$ solution. In the $0.5 \mathrm{M} \mathrm{H}_{2} \mathrm{SO}_{4}$ solutions (Fig. 3(b)), the curve of the self-corrosion potential is very similar with the corrosion current indicating that the corrosion 
resistance is not significantly different. Compared to the coating, $316 \mathrm{~L}$ stainless steel has higher self-corrosion potential and lower corrosion current, indicating little corrosion tendency. In addition, the passivation current density of the $316 \mathrm{~L}$ stainless steel $\left(1.18 \times 10^{-5} \mathrm{~A} \cdot \mathrm{cm}^{-2}\right)$ is far lower than the coating $\left(1.98 \times 10^{-3} \mathrm{~A} \cdot \mathrm{cm}^{-2}\right)$, which revealed that the corrosion resistance of $316 \mathrm{~L}$ stainless steel in $0.5 \mathrm{M} \mathrm{H}_{2} \mathrm{SO}_{4}$ solutions is slightly better than the coating. Fig. 3(c) demonstrates the self-corrosion current density of Fe-based amorphous coating and 316L stainless steel is low, but the corresponding self-corrosion potential is $-994 \mathrm{mV}$ and - $418 \mathrm{mV}$, respectively. Compared with $0.5 \mathrm{M} \mathrm{H}_{2} \mathrm{SO}_{4}$ solution, the corrosion potential low about three times. Besides, passivation film breakdown voltage is $0.5 \mathrm{~V}$ and $0.2 \mathrm{~V}$. The results showed that single coatings and 316L had higher corrosion tendency and worse local corrosion resistance in $\mathrm{NaOH}$ solutions. It is more than that the self-corrosion potential and overpassivation potential of amorphous coating are significantly lower than $316 \mathrm{~L}$. It indicated that the corrosion resistance of amorphous coating is inferior to $316 \mathrm{~L}$ in $\mathrm{NaOH}$ solution. It can be also seen that with the addition of AT13 content, the current density of the amorphous coating increases gradually, and other electrochemical parameters decrease gradually. The range of activation increases, while the range of stable passivation decreased slightly, indicating that the formation of passivation film slowed down and the corrosion resistance weakened. Fe-based amorphous and composite coatings have better corrosion resistance in $\mathrm{NaCl}$ solution. 

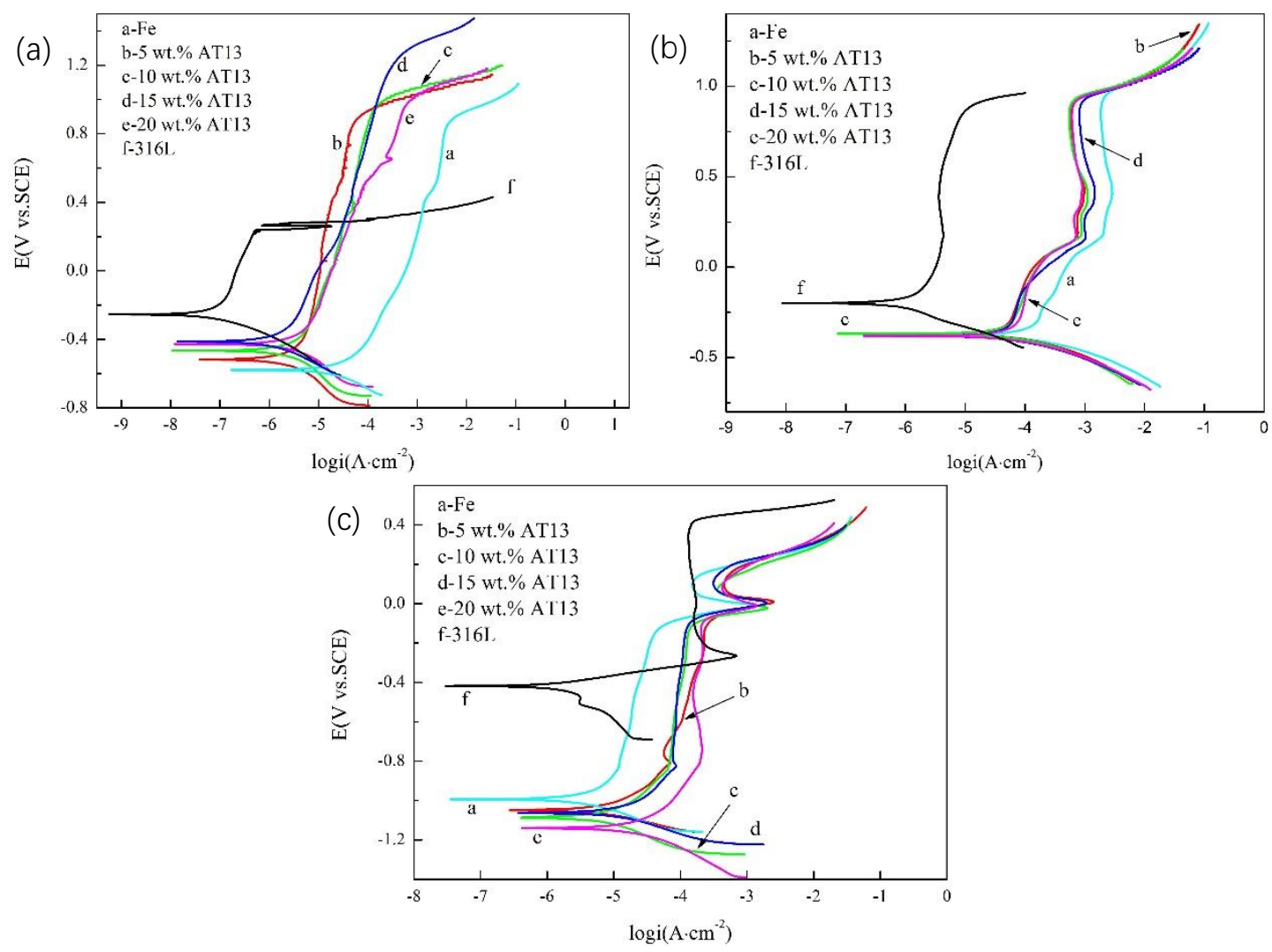

Fig. 3 Potentiodynamic polarization curves of different samples in

140 different corrosive solutions: (a) 3.5 wt.\% NaCl; (b) $0.5 \mathrm{M} \mathrm{H}_{2} \mathrm{SO}_{4}$; (c) 10 wt.\% $\mathrm{NaOH}$

Table 1 Summary of the electrochemical parameters

\begin{tabular}{|c|c|c|c|c|c|c|}
\hline $\begin{array}{c}\text { Corrosive } \\
\text { medium }\end{array}$ & Coating & $\begin{array}{c}\mathrm{E}_{\text {corr }} / \mathrm{m} \\
\mathrm{V} \\
\end{array}$ & $\begin{array}{c}\mathrm{i}_{\text {corr }} / \mathrm{A} \\
\mathrm{cm}^{-2} \\
\end{array}$ & $\begin{array}{c}\mathrm{i}_{\text {pass }} / \mathrm{A} \\
\mathrm{cm}^{-2} \\
\end{array}$ & $\mathrm{E}_{\mathrm{tr}} / \mathrm{mV}$ & $\begin{array}{c}\text { Corrosion } \\
\text { rate/mpy }\end{array}$ \\
\hline \multirow{6}{*}{$3.5 \% \mathrm{NaCl}$} & $\mathrm{Fe}$ & -580 & $\begin{array}{c}5.14 \times 10^{-} \\
5\end{array}$ & $\begin{array}{c}5.42 \times 10^{-} \\
3\end{array}$ & 867 & 25.06 \\
\hline & 5 wt. $\%$ AT 13 & -519 & $\begin{array}{c}7.50 \times 10^{-} \\
6\end{array}$ & $\begin{array}{c}6.23 \times 10^{-} \\
5\end{array}$ & 905 & 6.47 \\
\hline & $\begin{array}{c}10 \text { wt. } \% \\
\text { AT13 }\end{array}$ & -467 & $\begin{array}{c}5.01 \times 10^{-} \\
6\end{array}$ & $\begin{array}{c}1.12 \times 10^{-} \\
4\end{array}$ & 993 & 5.49 \\
\hline & $\begin{array}{c}15 \text { wt. } \% \\
\text { AT13 }\end{array}$ & -411 & $\begin{array}{c}1.75 \times 10^{-} \\
6\end{array}$ & $\begin{array}{c}5.37 \times 10^{-} \\
4\end{array}$ & 1236 & 2.07 \\
\hline & $\begin{array}{c}20 \text { wt. } \% \\
\text { AT13 }\end{array}$ & -430 & $\begin{array}{c}4.06 \times 10^{-} \\
6\end{array}$ & $\begin{array}{c}6.94 \times 10^{-} \\
4\end{array}$ & 1012 & 4.60 \\
\hline & $316 \mathrm{~L}$ & -257 & $\begin{array}{c}1.10 \times 10^{-} \\
7\end{array}$ & $\begin{array}{c}8.07 \times 10^{-} \\
7\end{array}$ & 286 & 0.55 \\
\hline
\end{tabular}




\begin{tabular}{|c|c|c|c|c|c|c|}
\hline & $\mathrm{Fe}$ & -376 & $\begin{array}{c}1.47 \times 10^{-} \\
4\end{array}$ & $\begin{array}{c}1.98 \times 10^{-} \\
3\end{array}$ & 919 & 65.31 \\
\hline \multirow{4}{*}{$\begin{array}{c}0.5 \mathrm{M} \\
\mathrm{H}_{2} \mathrm{SO}_{4}\end{array}$} & 5 wt. $\%$ AT 13 & -368 & $\begin{array}{c}6.29 \times 10^{-} \\
5\end{array}$ & $\begin{array}{c}5.93 \times 10^{-} \\
4\end{array}$ & 904 & 57.81 \\
\hline & $\begin{array}{c}10 \text { wt. } \% \\
\text { AT13 }\end{array}$ & -367 & $\begin{array}{c}5.25 \times 10^{-} \\
5\end{array}$ & $\begin{array}{c}6.24 \times 10^{-} \\
4\end{array}$ & 892 & 48.24 \\
\hline & $\begin{array}{c}15 \text { wt. } \% \\
\text { AT13 }\end{array}$ & -380 & $\begin{array}{c}6.51 \times 10^{-} \\
5\end{array}$ & $\begin{array}{c}8.47 \times 10^{-} \\
4\end{array}$ & 896 & 59.80 \\
\hline & $\begin{array}{c}20 \text { wt. } \% \\
\text { AT13 }\end{array}$ & -383 & $\begin{array}{c}7.95 \times 10^{-} \\
5\end{array}$ & $\begin{array}{c}6.52 \times 10^{-} \\
4\end{array}$ & 898 & 73.10 \\
\hline \multirow{7}{*}{$\begin{array}{c}10 \% \mathrm{NaO} \\
\mathrm{H}\end{array}$} & $316 \mathrm{~L}$ & -199 & $\begin{array}{c}4.24 \times 10^{-} \\
6\end{array}$ & $\begin{array}{c}1.18 \times 10^{-} \\
5\end{array}$ & 877 & 3.90 \\
\hline & $\mathrm{Fe}$ & -994 & $\begin{array}{c}7.84 \times 10^{-} \\
6\end{array}$ & $\begin{array}{c}5.46 \times 10^{-} \\
5\end{array}$ & -125 & 9.05 \\
\hline & 5 wt. $\%$ AT 13 & -1049 & $\begin{array}{c}2.39 \times 10^{-} \\
5\end{array}$ & $\begin{array}{c}2.46 \times 10^{-} \\
4\end{array}$ & -117 & 15.18 \\
\hline & $\begin{array}{c}10 \text { wt. } \% \\
\text { AT13 }\end{array}$ & -1096 & $\begin{array}{c}1.68 \times 10^{-} \\
5\end{array}$ & $\begin{array}{c}1.47 \times 10^{-} \\
4\end{array}$ & -102 & 15.40 \\
\hline & $\begin{array}{c}15 \text { wt.\% } \\
\text { AT13 }\end{array}$ & -1063 & $\begin{array}{c}2.38 \times 10^{-} \\
5\end{array}$ & $\begin{array}{c}1.28 \times 10^{-} \\
4\end{array}$ & -98 & 21.89 \\
\hline & $\begin{array}{c}20 \text { wt. } \% \\
\text { AT13 }\end{array}$ & -1145 & $\begin{array}{c}4.40 \times 10^{-} \\
5\end{array}$ & $\begin{array}{c}2.16 \times 10^{-} \\
4\end{array}$ & -96 & 40.45 \\
\hline & $316 \mathrm{~L}$ & -418 & $\begin{array}{c}1.02 \times 10^{-} \\
6\end{array}$ & $\begin{array}{c}1.48 \times 10^{-} \\
4\end{array}$ & 415 & 0.94 \\
\hline
\end{tabular}

\section{Analysis of corrosion morphology in different media}

Fig. 4 depicts the surface corrosion morphologies of the amorphous coating, 15 wt.\%AT13 composite coating and 316L after dynamic potential scanning to the over-

145 passivation interval in $\mathrm{NaCl}$ solution. It is clearly seen that the severe corrosion of $\mathrm{Fe}-$

146 based amorphous coating in the spray pores and the edges of unmelted particles (Fig.

147 4a). Besides, amounts of evenly distributed corrosion holes appear on the surface 148 (marked with white dotted circle). The results demonstrate that the coating mainly 149 produces local pitting corrosion, the passivation film has failed, and the coating matrix 150 dissolves rapidly. It can be seen that the corrosion of composite coating is obvious 151 in holes and crevices, and the number of corrosion holes on the surface of the composite 
152

coating is significantly less than that of pure coating (Fig. 4b), indicating that the composite coating has stronger resistance to local corrosion than the pure amorphous coating. The surface of the 316L stainless steel presents marked pitting corrosion hole $(>60 \mu \mathrm{m})$ (Fig. 4c). The size of that is much larger than the corrosion hole of the coating. Hence the local corrosion resistance of the $316 \mathrm{~L}$ stainless steel is inferior than the coating.
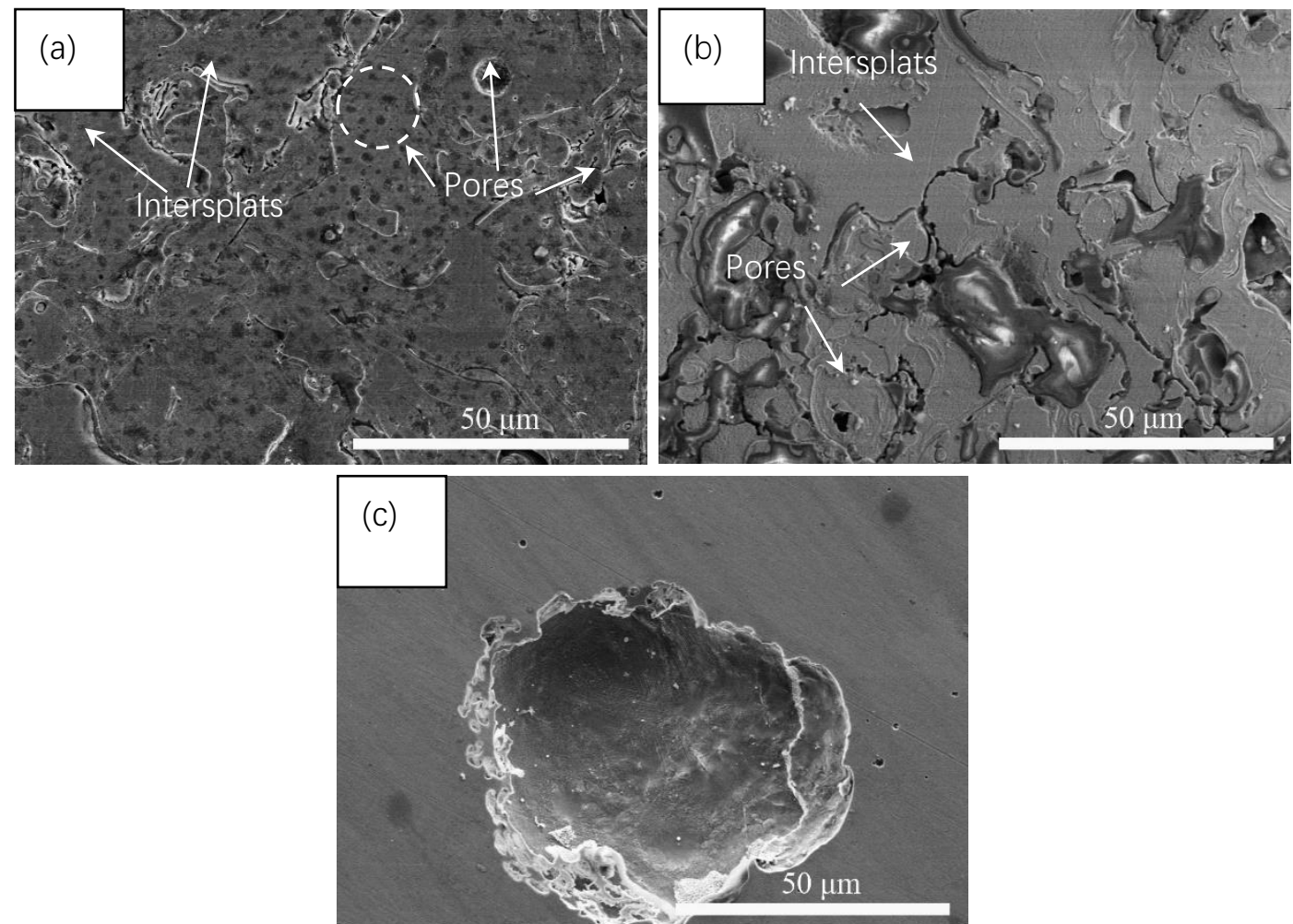

Fig. 4 SEM images of potentiodynamic polarization of different samples in 3.5wt.\%

$\mathrm{NaCl}$ solution: (a) Fe-based amorphous coating; (b) 15 wt.\%AT13 composite coating;

$$
\text { (c) } 316 \mathrm{~L}
$$

The SEM images of the surface morphologies of the three samples after potentiodynamic polarization in $0.5 \mathrm{M} \mathrm{H}_{2} \mathrm{SO}_{4}$ solution are shown in Fig. 5. As seen in Fig. 5a, amounts of pitting holes appear on the Fe-based amorphous coating surface. 
174 Obviously, the size of pitting holes of the coating in $0.5 \mathrm{M} \mathrm{H}_{2} \mathrm{SO}_{4}$ solution is much larger

175 than that of the coating in $\mathrm{NaCl}$ solution and crevice corrosion is more distinct with accompanied by lamellar shedding. Compared with the pure coating, composite coating

177 remains the coating surface morphology (Fig. 5b), which means 316L stainless steel

178 has the best corrosion resistance in $0.5 \mathrm{M} \mathrm{H}_{2} \mathrm{SO}_{4}$ solution and the corrosion resistance

179 of the composite coating is slightly better than of the single coating. Nevertheless, the corrosion resistance of the coating in $0.5 \mathrm{M} \mathrm{H}_{2} \mathrm{SO}_{4}$ solution is lower than that in $3.5 \mathrm{wt} . \%$

$\mathrm{NaCl}$ solution. For 316L stainless steel, it has no obvious corrosion change, showing
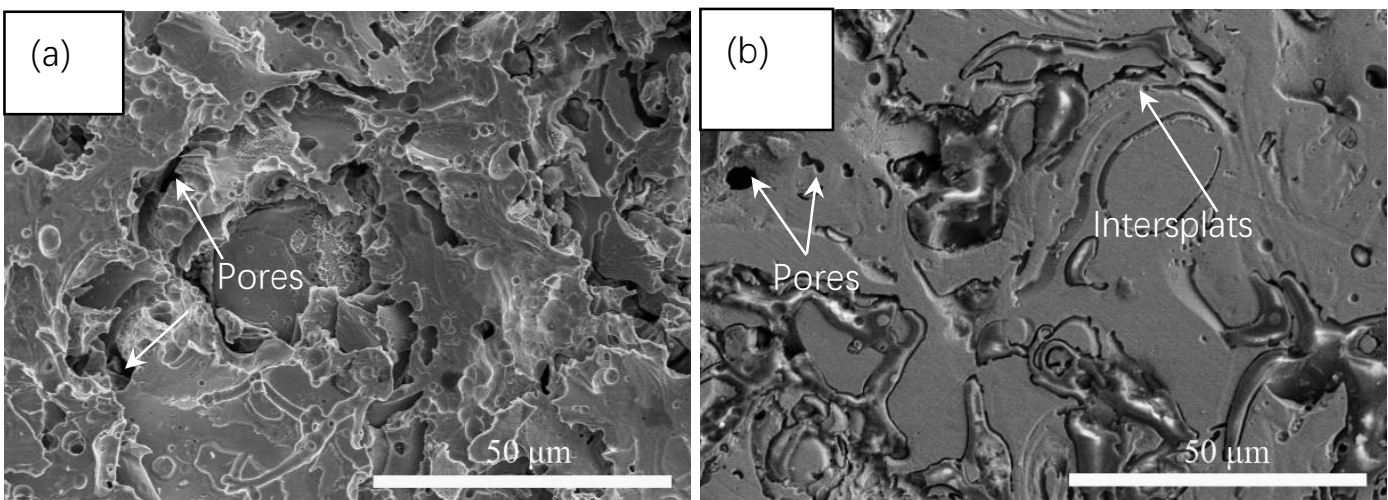

(c)

Fig.5 SEM images of potentiodynamic polarization of different samples in $0.5 \mathrm{M}$ 
Fig. 6 presents the SEM images of potentiodynamic polarization of different samples

in 10 wt.\% $\mathrm{NaOH}$ solution. A layer of reddish-brown corrosion product on the surface of the Fe-based amorphous coating with a large number of lamellar shedding (Fig. 6a).

The reason of corrosion is mainly the sodium hydroxide solution penetrates the interface between the coating and the substrate through the coating gaps and holes during the dynamic potential scanning. Meanwhile, the coating dissolved rapidly and the matrix reacts with the corrosion solution to produce a large amount of $\mathrm{Fe}(\mathrm{OH})_{2}$ and $\mathrm{Fe}(\mathrm{OH})_{3}$. In comparison with single coating, composite coating surface is easier to peel off (Fig. 6b), which is probably related to chemical relation. By further analysis, the presence of $\gamma-\mathrm{Al}_{2} \mathrm{O}_{3}$ phase in the composite coating reacted with the $\mathrm{NaOH}$ solution which accelerated the corrosion of coating. These observations reveal that with the addition of AT13 ceramic phase, the corrosion resistance of Fe-based amorphous coating obviously deteriorates in alkaline environment. Conversely, in the case of $316 \mathrm{~L}$ stainless steel, only a few micro-sized pitting holes are observed on the surface (Fig. 6c), showing the best corrosion resistance, which is consistent with result of the

polarization curve analysis.

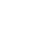



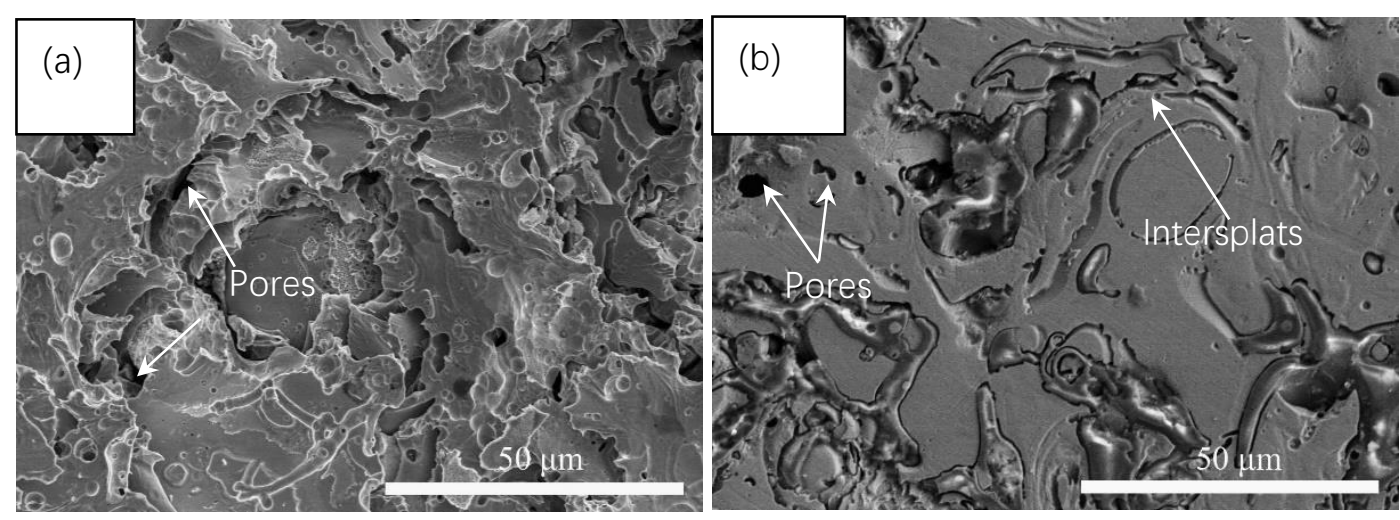

\section{(c)}

\section{Immersion test}

\subsection{EIS measurements}

Potentiodynamic polarization and electrochemical impedance spectroscopy (EIS) measurements were performed to evaluate the corrosion resistance performances of coatings. The above experimental results show that the coating exhibit excellent corrosion resistance in $3.5 \mathrm{wt} . \% \mathrm{NaCl}$ solution. In order to better evaluate the corrosion failure process of different coatings, long term immersion experiments in 3.5 wt.\% $\mathrm{NaCl}$ solution combined with EIS measurements were carried out to analysis corrosion behavior of the coatings. 
Fig. 7 illustrates the EIS plots of different coatings completely immersed in 3.5 wt.\%

241

$\mathrm{NaCl}$ solution for 28 days. The Nyquist plots recorded at different period of immersion time of the coatings are shown in Fig. 7a, c, e, g, i and panels b, d, f, h and j of Fig. 7 are the corresponding plots of phase angle versus logarithmic frequency. There exist two stages of corrosion process of coatings: $0 \mathrm{~d}$ and $1 \mathrm{~d}-28 \mathrm{~d}$. The data recorded at the initial stage of corrosion exhibit two time constants due to relatively high porosity of the coating. At the initial stage of immersion, $\mathrm{Cl}^{-}$ions present in solution has penetrated into the coating from cracks and holes, and the galvanic corrosion reaction of the chrome-poor and chrome-rich regions occurred near the interface between the unmelted particles and layers to form a microcell ${ }^{[13]}$.

For single coating, the impedance value is reduced from $1705 \Omega \cdot \mathrm{cm}^{2}$ to $731 \Omega \cdot \mathrm{cm}^{2}$. And the impedance value of the $5 \mathrm{wt} \%$ AT13 composite coating is reduced from 2587 $\Omega \cdot \mathrm{cm}^{2}$ to $2160 \Omega \cdot \mathrm{cm}^{2}$. It is difficult to distinguish the two time constants due to the capacitance arcs of the low frequency is not clear ${ }^{[14]}$. One time constant was in high frequency range related to the capacitance impedance of the coating. The other constant was in low frequency range related to charge transfer resistance and a double-layer capacitance between the solution/coating interface. As immersion time increased, the value of the resistance changed within a small range. During the 0day immersion, the phase angle in the Bode phase plots (Fig. 7b and Fig. 7d) presents a maximum. With the immersion increasing, the high frequency phase angle is shifted to left and the curve drops, indicating more and more defects would be formed in coating due to corrosion. In Fig. 7e, the Bode impedance plots of $10 \mathrm{wt} \%$ AT13 composite coating shows two 
continuous semi-circle shape. With the immersion increasing, the radius of capacitance arc increased gradually, suggesting that the porosity of coating was further reduced and the resistance of the passivation membrane to the electrolyte was enhanced. With the immersion time to 10 day, the resistance value decreased gradually and then fluctuate within a small range. The EIS plots of $15 \mathrm{wt} . \%$ and $20 \mathrm{wt} . \%$ AT13 composite coatings in 3.5 wt. $\% \mathrm{NaCl}$ solution for the 28 days are shown in Fig. $7 \mathrm{~g}-\mathrm{j}$. There existed two stages of the corrosion progress for the coatings: 0 day and after 1 day. At the 0 day, the single capacitance resistance arc occurred in Bode impedance plots (shown in Fig. $7 \mathrm{~g}$ and Fig. 7i). It can be seen that the complete shielding layer was existed in the composite coating, which prevented the corrosion effectively. The resistance value of 15 wt. $\%$ AT13 composite coating was $2780 \Omega \cdot \mathrm{cm}^{2}$ in the same time. Compared to 20 wt. $\%$ AT13 composite coating, the radius of semi-circle arc was bigger, indicating that the corrosion resistance of $15 \mathrm{wt} . \%$ AT13 composite coating is better. After 1day immersion, the Bode impedance plots showed two time constant, indicating that the solution had reached oxide layer interface and the micro-galvanic reaction.

From the EIS plots of pure amorphous coating and composite coating, we can learn that the radius of the capacitance resistance arc was the biggest when the addition of AT13 is 15 wt.\%, which suggested the corrosion resistance is improved. When immersed for just 28 day, all coatings have not shown the characteristic Warburg impedance caused by the diffusion of sodium chloride solution, indicating that the coatings haven't yet lose the protective effect of the substance and have good corrosion resistance. 
284

285

286

287

288

289

290

291

292

293

294

295

296

297

298

299

300

301

302

303
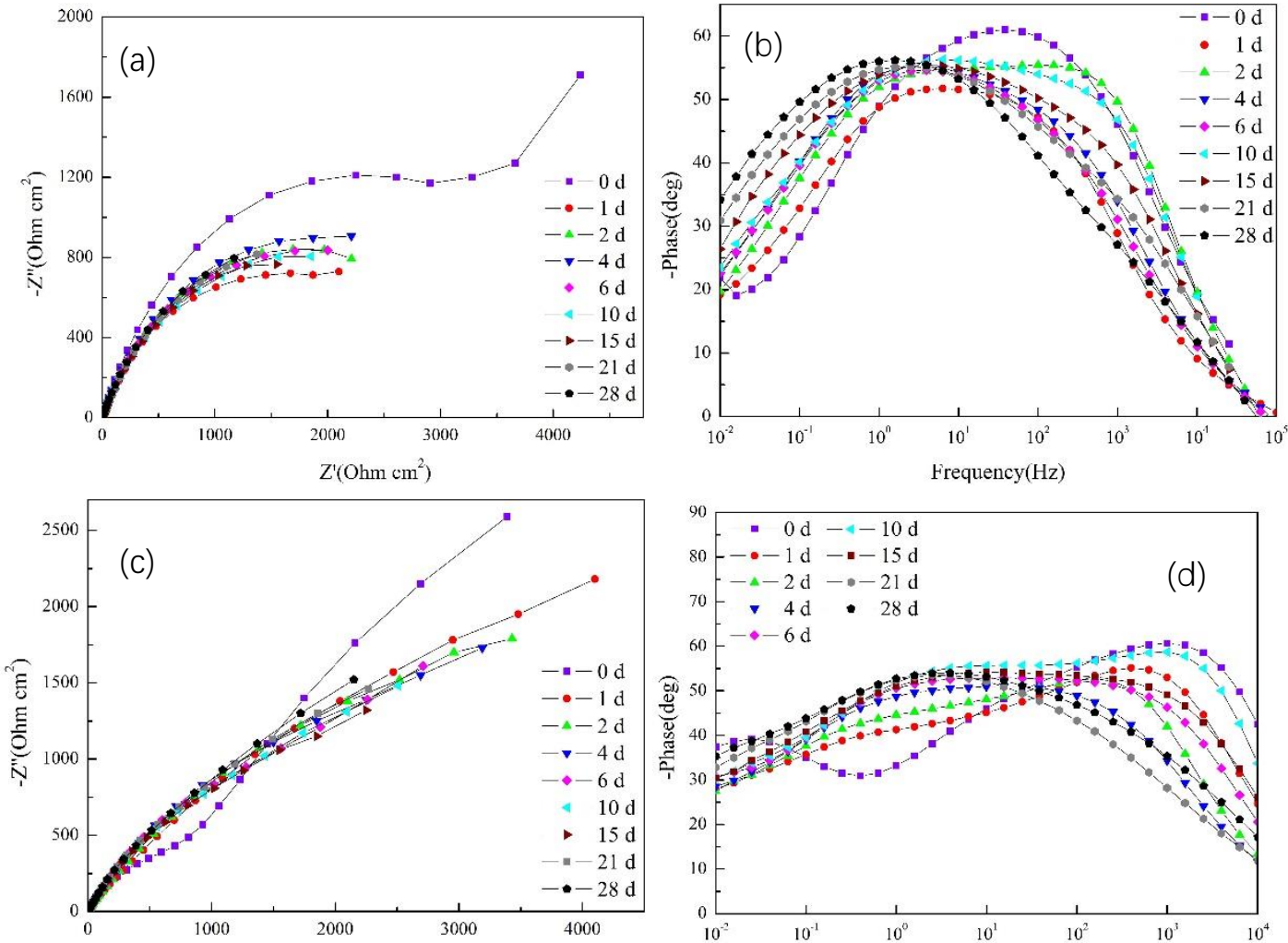

$\mathrm{Z}^{\prime}\left(\mathrm{Ohm} \mathrm{\textrm {cm } ^ { 2 } )}\right.$
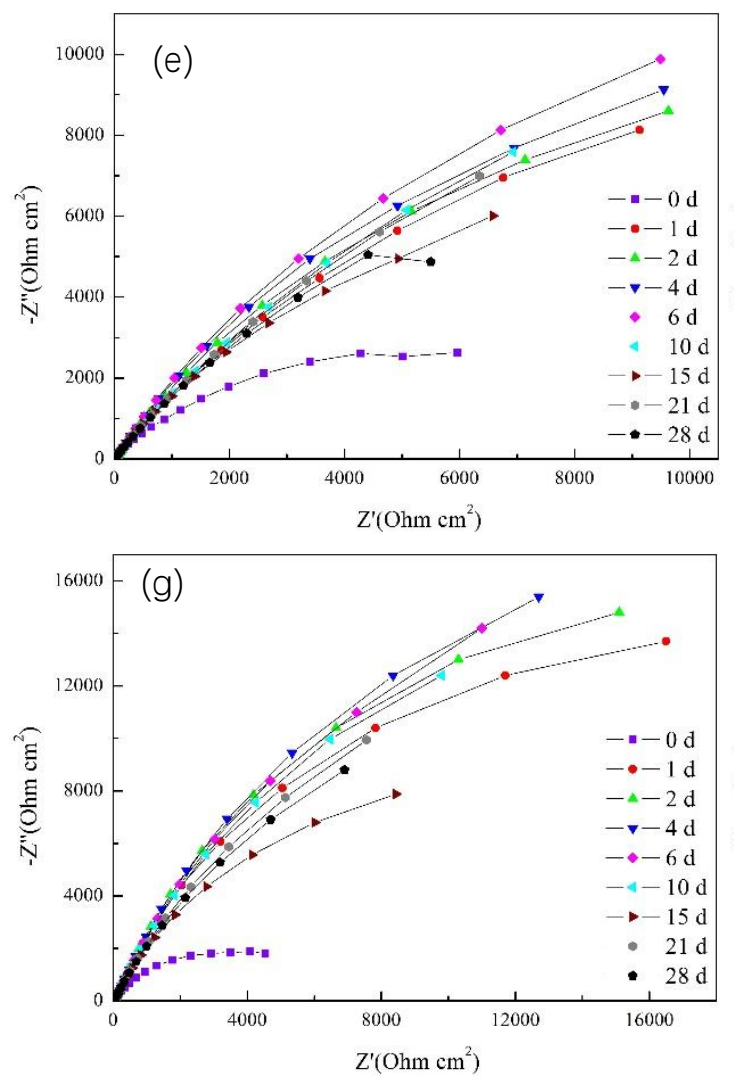

(d)
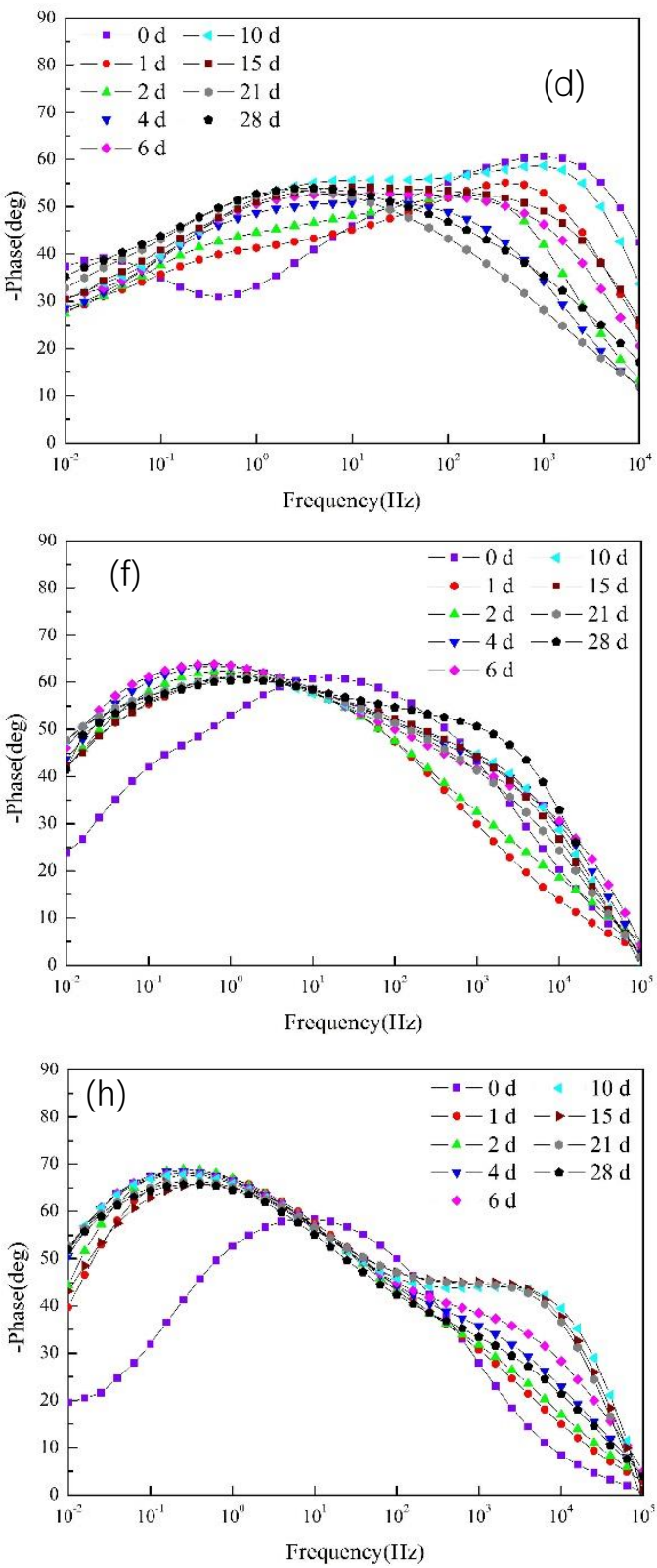

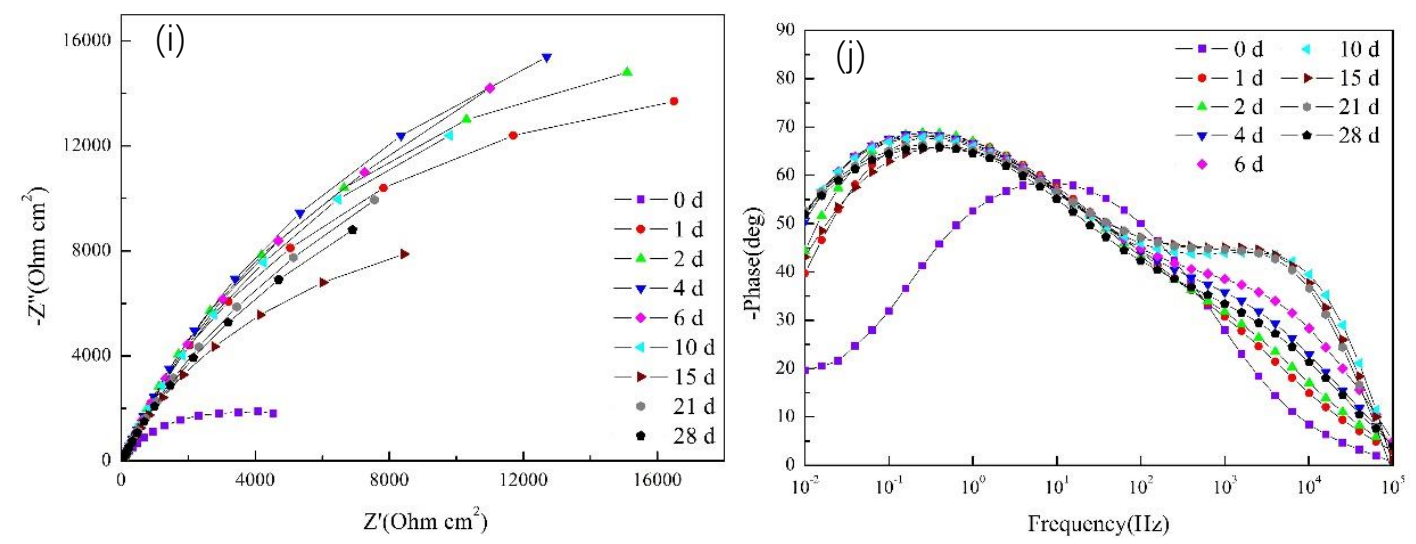

Fig. 7 EIS plots of pure Fe-based coating,5 wt.\%,10 wt.\%,15 wt.\% and 20 wt.\%AT13 composite coatings cafter different immersion times: of the resistance of electrolyte solution $(\mathrm{Rs})$, the CPE of coating $\left(\mathrm{Q}_{\mathrm{c}}\right)$ in parallel with the resistance of coating $\left(\mathrm{R}_{\mathrm{c}}\right)$ and the CPE of double layer $\left(\mathrm{Q}_{\mathrm{dl}}\right)$ in parallel with the charge transfer resistance $\left(\mathrm{R}_{\mathrm{t}}\right.$ ). Model B (Fig. 8b) was applied to the EIS data simulation of Fe-based coating, 5 wt.\%, 10 wt.\% AT13 composite coatings and later stage corrosion of 15 wt. $\%$ and 20 wt. $\%$ AT13 composite coatings. For model B, CPE-ct represents a double-layer capacitance between oxide layer/coating interface. $R_{c t}$ represents charge transfer resistance. 
321

322

323

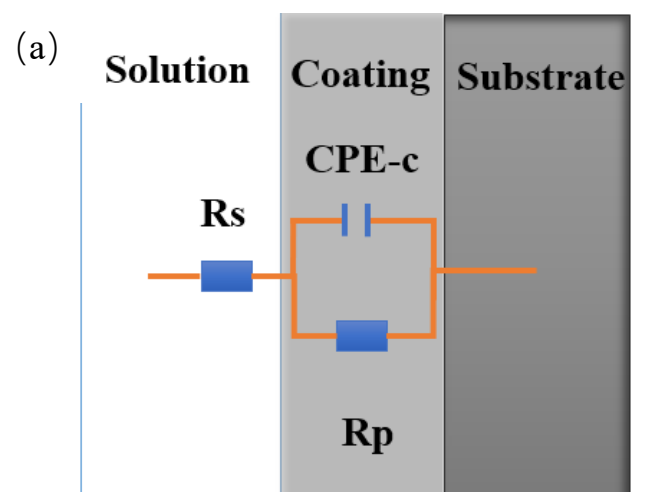

(b)

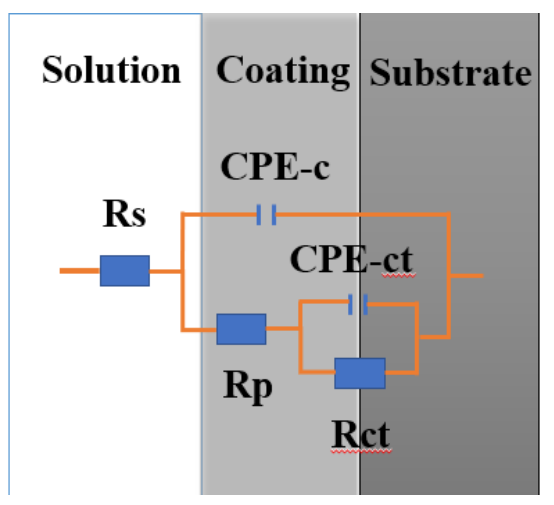

Fig. 8 The fitted equivalent circuits: (a) initial stage corrosion of 15 wt. $\%$ and 20 wt.\% AT13 composite coatings; (b) Fe-based coating, 5 wt.\%, 10 wt.\%AT13 composite
coatings and later stage corrosion of 15 wt. $\%$ and 20 wt.\% AT13 composite coatings The variation of electrochemical parameters for EIS spectra of coating with corrosion time was shown in Fig. 9. At the initial stage, the maximum value of $R_{p}$ was $8.51 \times 10^{3}$ $\Omega \cdot \mathrm{cm}^{2}$ (Fig. 9a), which implied that dense passivation produced in the coating surface to prevent $\mathrm{Cl}^{-}$ion erosion. Compared to other coatings, the corrosion resistance of 15 wt.\% AT13 composite coating is best. As the immersion time increased, the value of $R_{p}$ decreased sharply and then kept steady indicating that the corrosion products dissolved into the solution gradually ${ }^{[15]}$. Fig. $9 \mathrm{~b}$ showed the values of CPE-c increased significantly when it increased to 21 day, suggesting that the protective ability of Febased and 5 wt.\% AT13 composite coatings greatly weakened due to the increase of coating porosity. In Fig. 9c, we can see that the values of $\mathrm{R}_{\mathrm{ct}}$ increased correspondingly with the addition of ceramic phase which indicated the composite coating enhanced a hindrance to the corrosion solution. This proved that the corrosion resistance of $15 \mathrm{wt} . \%$ AT13 composite coating is more superior to others, which is consistent with EIS result. 

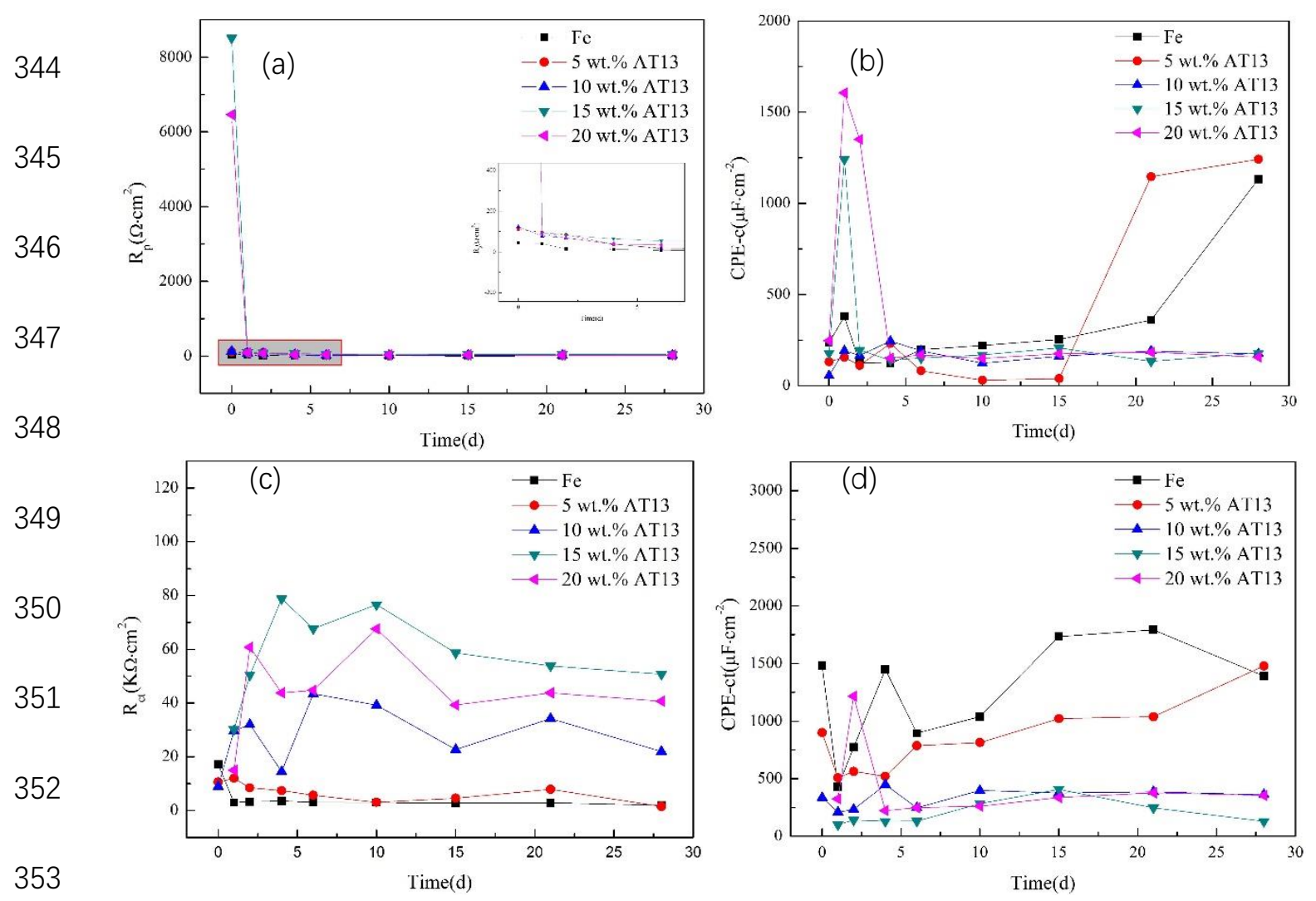

Fig. 9 The variation of electrochemical parameters for EIS spectra of coating with

5.2 The analysis of surface element amorphous coating and 15 wt.\% AT13 composite coating were investigated by XPS. Fig. 10 presented the XPS fine spectrum of Fe2p, Cr2p and Mo3d in the surface

361 passivation. As shown in Fig. 10a and Fig. 10b, the Fe2p $\mathrm{p}_{3 / 2}$ spectrum consists of overlapped four peaks at $707 \mathrm{eV}, 709 \sim 714 \mathrm{eV}$, which matches the $\mathrm{Fe}^{2+}$ and $\mathrm{Fe}^{3+}$ oxidation states $^{[14]}$. In Fig. 10c and Fig. $10 d$, the Cr2p p $_{3 / 2}$ spectrum can be resolved into three peaks at $574 \mathrm{eV}, 576 \mathrm{eV}$ and $578 \mathrm{eV}$. The peak at $574 \mathrm{eV}, 576 \mathrm{eV}$ and $578 \mathrm{eV}$ 
365

represent $\mathrm{Cr}^{0}$ metallic state, $\mathrm{Cr}^{3+}$ oxidation state and $\mathrm{Cr}^{6+}$ oxidation state, respectively ${ }^{[16]}$. Moreover, the $\mathrm{Co}^{0}$ metallic state is just a part of $\mathrm{Cr} 2 \mathrm{p}_{3 / 2}$ spectrum. The fitting results of the Mo3d spectrum were shown in Fig. 10e, f. Meanwhile, two peaks at $228 \sim 229 \mathrm{eV}$ and $230 \sim 231 \mathrm{eV}$ were attributed to the $\mathrm{Mo}^{0}$ metallic state. The peaks at 229 230 eV and 232 233 eV could be associated with $\mathrm{Mo}^{3+}$ oxidation state. The peaks at $233 \sim 234 \mathrm{eV}$ and $234 \sim 236 \mathrm{eV}$ were attributed to $\mathrm{Mo}^{4+}$ oxidation state.
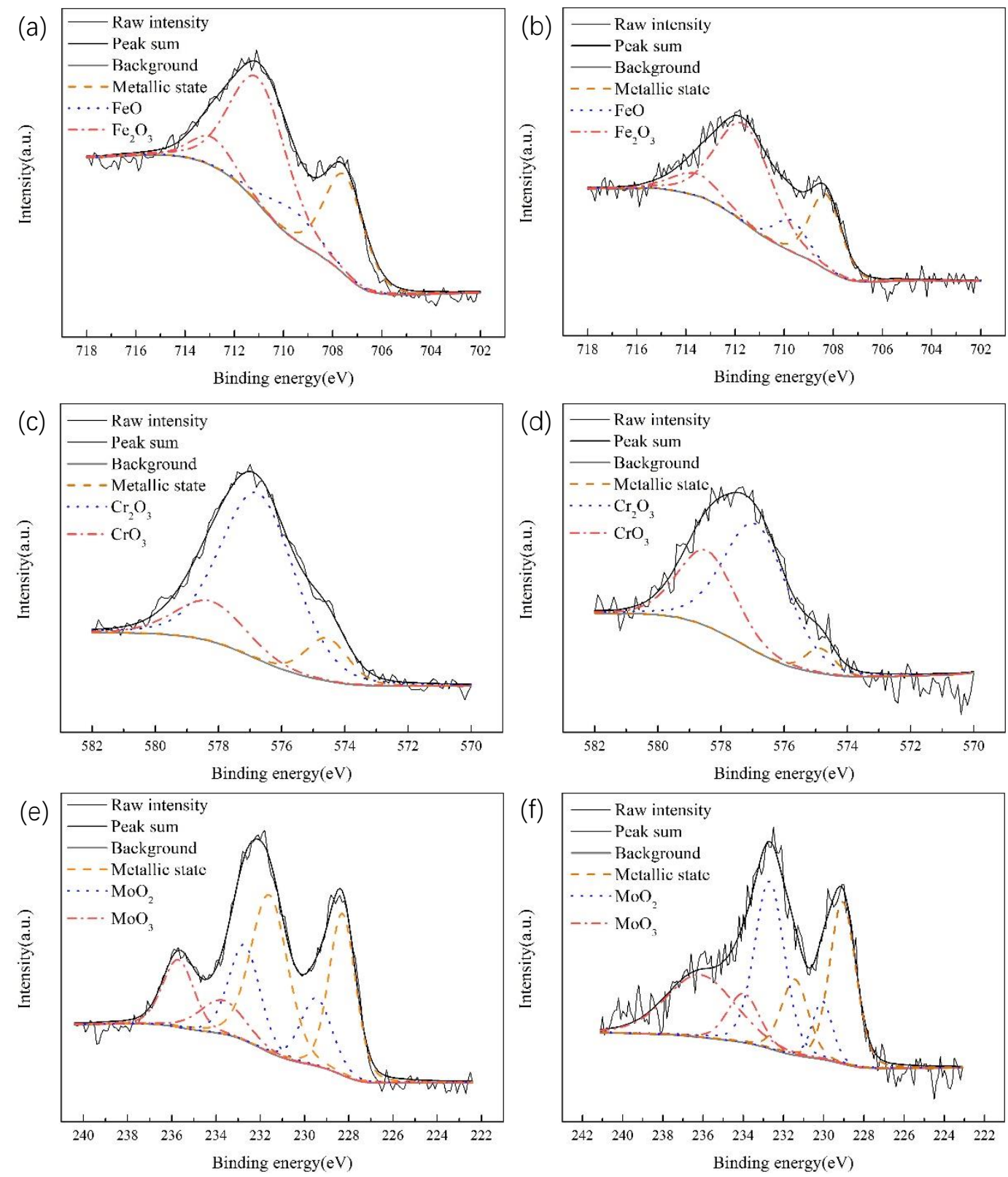

Fig. 10 XPS spectrum: (a)(c)(e) amorphous coating; 
The quantitative analysis of XPS results can be easily understand the corrosion resistance mechanism of the coatings. We suppose that the metal ions in the oxidation state are derived from the composition of the passivation film, and the metal ions correspond to the passivation film/coating metal interface. The relative composition of passivation film and the interface can be determined. Fig. 11 shows that cationic component in the passivation film and atomic component at the coating interface. For comparison, the passivation film of pure coating exhibited a higher Fe oxide content and a lower Mo oxide content than the composite coating. In addition, the Mo3d spectrum of the composite coating surface was mainly $\mathrm{Mo}^{4+}$ oxide state. It was reported

[17] that $\mathrm{Mo}^{4+}$ oxide in the passivation film can greatly improve the stability of passivation film, thereby further enhance the local corrosion resistance. In this study, the corrosion resistance of composite coating is better than that of the single coating.

This result is consistent with the EIS data mentioned above.

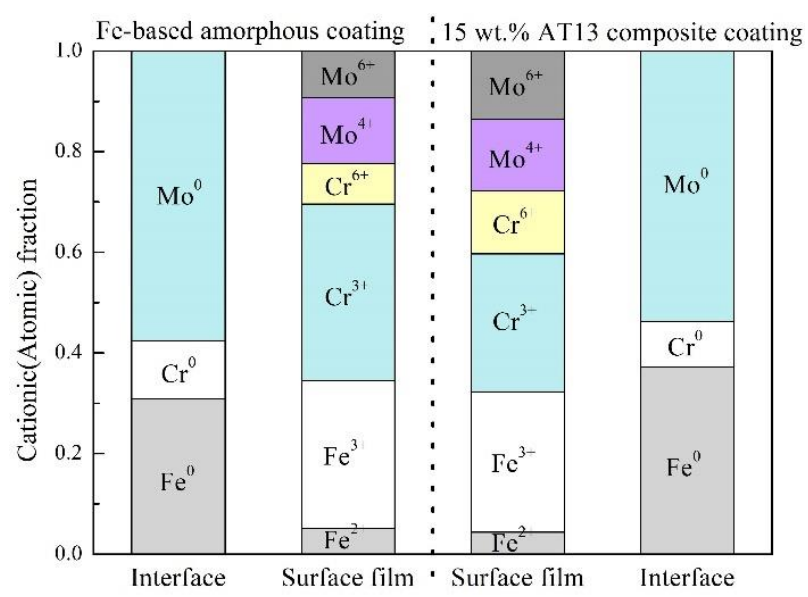

Fig. 11 Cationic fractions of the oxide species and atomic fractions of the metallic 
409

\subsection{The analysis of the corrosion morphology}

To clarify the mechanism of the corrosion for the coatings, the surface corrosion morphologies of the pure Fe-based coating and that of the 15 wt.\% AT13 composite coating after immersion for 28 days was investigated by SEM. As shown in Fig. 12, the corrosion of coating surface was uneven. In addition, the corrosion preferentially occurred at the edge of pore defect and the oxide ${ }^{[18]}$. Nevertheless, the corrosion of the composite coating is less serious. This is because that many pores and micro-cracks occurred in the single coating, and the $\mathrm{Cr}$ - rich and Cr-poor regions at the oxide edge formed the micro-galvanic corrosion, which will become a preferential corrosion region, leading to the ion penetration and corrosion reaction. As the corrosion time extends, the coating peeled off and formed obvious pits. It indicates that the corrosion resistance of coating is further deteriorated, but a large amount of corrosion products have not yet accumulated.
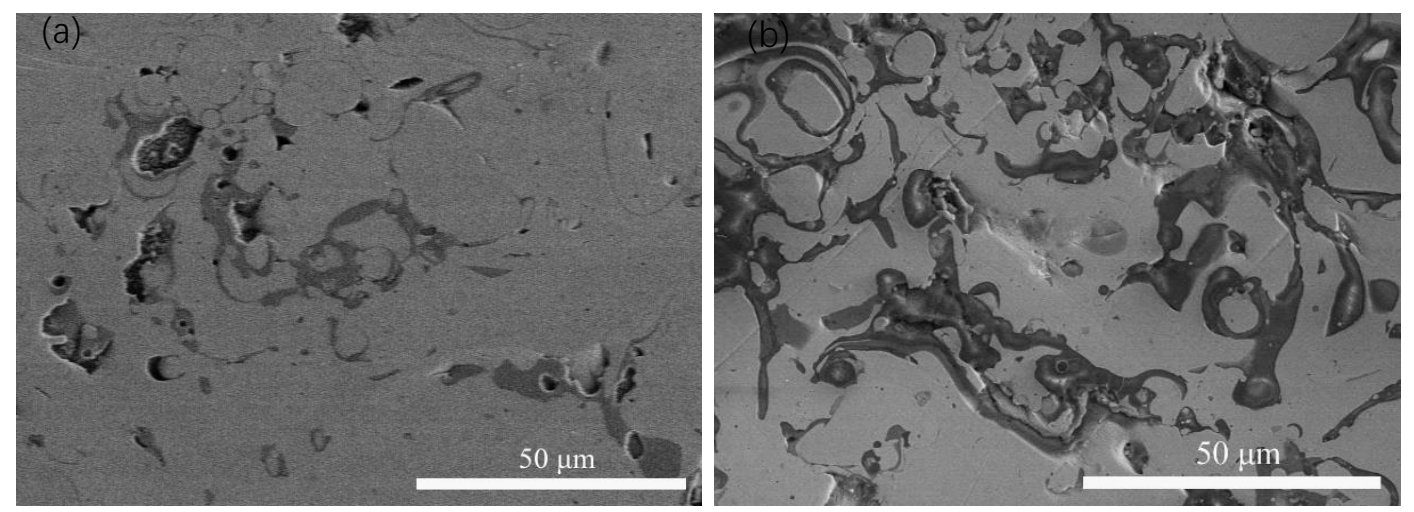

Fig. 12 Corrosion morphology after immersion in 3.5 wt. $\% \mathrm{NaCl}$ solution for 28 days:

(a) pure Fe-based coating; (b) 15 wt.\% AT13 composite coating 
431

432

433

434

\section{Research on long-term corrosion mechanism in $\mathrm{NaCl}$ solution}

The long-term corrosion mechanism diagram of composite coating is illustrated in Fig. 13. As shown in Fig. 13a, there are some pore defects on the surface of the sample. Meanwhile, there are mainly some interlayer gaps composed of oxide. Due to the flying oxidation of particles during plasma spraying, $\mathrm{Cr}$ depleted areas are formed around the pores ${ }^{[19]}$. However, when the coating was fully immersed, the pores on the surface will be filled in $\mathrm{NaCl}$ solution. After that, the $\mathrm{Cr}$ depleted area around the pores will be quickly dissolved (shown in Fig. 13b). Thus, a typical crevice corrosion reaction at the micro-defects of the pores. At this time, the surrounding area will be further dissolved because of the location advantage of the extreme occlusion in the hole and the harsh corrosion environment. With the immersion time increases, the corrosion area of the pores increases and the depth of the corrosion also increases. It gradually connected with the internal closed pores and the intermediate layer, becoming a channel for corrosion ions to invade the coating/substance interface (Fig. 13c). In general, with the increase of AT13 content, the pore micro-defects and pore size in the composite coating reduces. It is resulted that the probability and rate of the crevice corrosion reduces, and the polarization test also shows lower corrosion current density and higher selfcorrosion potential. 


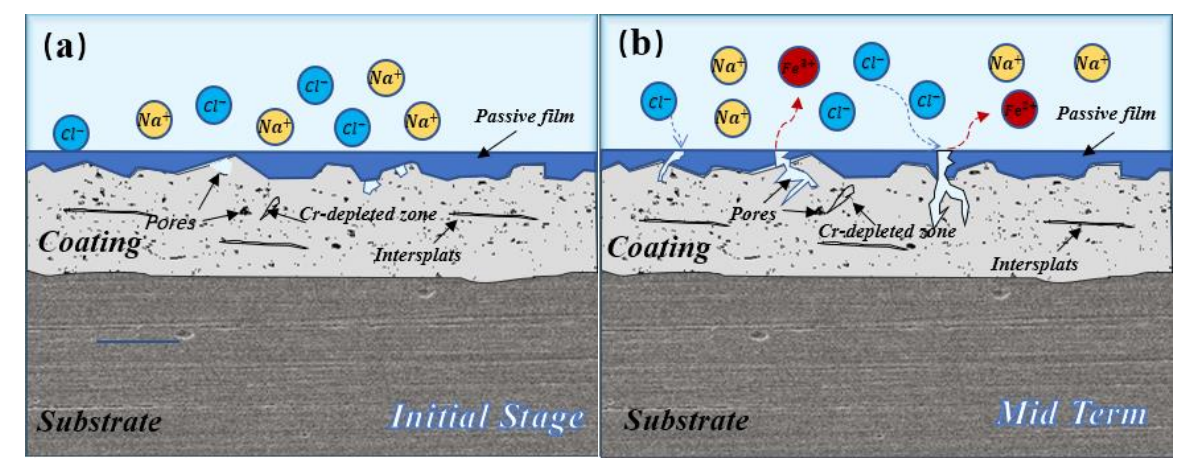

450

451

452

453

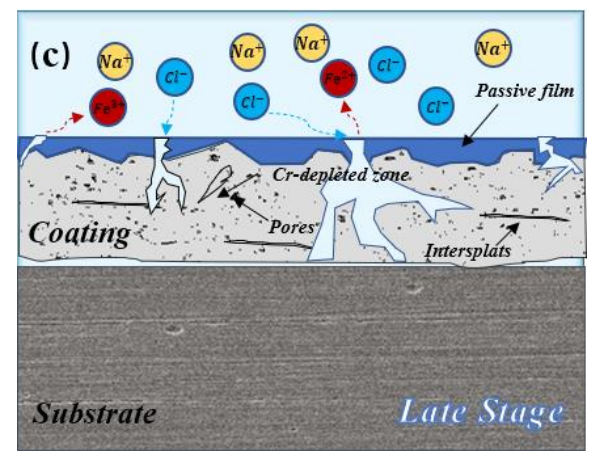

Fig. 13 The long-term corrosion mechanism diagram of composite coating: (a) initial stages of corrosion; (b) mid stages of corrosion; (c) late stages of corrosion

\section{Conclusion}

The coatings show the obvious passivation behavior in $3.5 \mathrm{wt} \% \mathrm{NaCl}$ solution, and the breakdown potential of the passivation film $(1.0 \mathrm{~V})$ was much higher than that of the $316 \mathrm{~L}$ stainless steels $(0.4 \mathrm{~V})$. As the content of AT13 increase to $15 \mathrm{wt} . \%$, the corrosion current density of coating reached the lowest and the self-corrosion potential was the highest. It indicates that the addition of AT13 phase effectively improves the corrosion resistance of the coating in simulated seawater.

Long term immersion corrosion was carried out on different coatings. The impedance spectroscopy test results showed that the protective effect of the coating was enhanced with the increase of the amount of the AT13. The equivalent circuit of pure coating, 5 wt.\% and 10 wt.\% AT13 amorphous coating is $\mathrm{R}(\mathrm{Q}(\mathrm{R}(\mathrm{QR})))$. And the 
464

465

equivalent circuit of the 15 wt. $\%$ and 20 wt.\% AT13 amorphous coating increases $(\mathrm{R}(\mathrm{QR}))$ to $(\mathrm{R}(\mathrm{Q}(\mathrm{R}(\mathrm{QR})))$.

\section{Acknowledgments}

This work was supported by the National Nature Science Foundation of China (No.51872072), The Excellent Youth Foundation of Jiangsu Scientific Committee (grant number: BK20190103), Special funding for the development of science and technology of Shanghai Ocean University (No. A2-0203-00-100231 and A2-2006-00200371).

\section{References}

[1] H. Zhang, Y. Hu, G. Hou, Y. An, G. Liu, The effect of high-velocity oxy-fuel spraying parameters on microstructure, corrosion and wear resistance of Fe-based metallic glass coatings. Journal of Non-Crystalline Solids 406, 37-44 (2014).

[2] H. S. Ni et al., High performance amorphous steel coating prepared by HVOF thermal spraying. Journal of Alloys and Compounds 467, 163-167 (2009).

[3] W. H. Wang, C. Dong, C. H. Shek, Bulk metallic glasses. Materials Science and Engineering: R: Reports 44, 4589 (2008).

[4] Y. Zhang et al., Microstructures and properties of high-entropy alloys. Progress in Materials Science 61, 1-93 (2014).

[5] C. Zhang et al., Optimizing process and the properties of the sprayed Fe-based metallic glassy coating by plasma spraying. Surface and Coatings Technology 319, 1-5 (2017).

[6] M. Yasir, C. Zhang, W. Wang, Y. Jia, L. Liu, Enhancement of impact resistance of Fe-based amorphous coating by A12O3 dispersion. Materials Letters 171, 112-116 (2016).

[7] S.-1. Wang, J.-c. Cheng, S.-H. Yi, L.-m. Ke, Corrosion resistance of Fe-based amorphous metallic matrix coating fabricated by HVOF thermal spraying. Transactions of Nonferrous Metals Society of China 24, 146-151 (2014).

[8] Y. Cai et al., The effect of TiC/A12O3 composite ceramic reinforcement on tribological behavior of laser cladding Ni60 alloys coatings. Surface and Coatings Technology 291, 222-229 (2016).

[9] Z. Chu et al., Corrosion Mechanism of Plasma-Sprayed Fe-Based Amorphous Coatings with High Corrosion Resistance. Journal of Thermal Spray Technology 29, 1111-1118 (2020).

[10] Z. Chu, F. Wei, X. Zheng, C. Zhang, Y. Yang, Microstructure and properties of TiN/Fe-based amorphous composite coatings fabricated by reactive plasma spraying. Journal of Alloys and Compounds 785, 206-213 (2019). [11] Z. Chu, X. Zheng, C. Zhang, J. Xu, L. Gao, Study the effect of AT13 addition on the properties of AT13/Febased amorphous composite coatings. Surface and Coatings Technology 379, (2019).

[12] Z. Chu et al., Characterization and tribology performance of Fe-based metallic glassy composite coatings fabricated by gas multiple-tunnel plasma spraying. Surface and Coatings Technology 292, 44-48 (2016). 
498

499

500

501

502

503

504

505

506

507

508

509

510

511

512

513

514

515

[13] R. Q. Guo et al., Study of structure and corrosion resistance of Fe-based amorphous coatings prepared by HVAF and HVOF. Corrosion Science 53, 2351-2356 (2011).

[14] Y. Yang, C. Zhang, Y. Peng, Y. Yu, L. Liu, Effects of crystallization on the corrosion resistance of Fe-based amorphous coatings. Corrosion Science 59, 10-19 (2012).

[15] J. M. Guilemany, J. Fernández, N. Espallargas, P. H. Suegama, A. V. Benedetti, Influence of spraying parameters on the electrochemical behaviour of HVOF thermally sprayed stainless steel coatings in $3.4 \% \mathrm{NaCl}$. Surface and Coatings Technology 200, 3064-3072 (2006).

[16] J. C. Farmer et al., Corrosion resistance of thermally sprayed high-boron iron-based amorphous-metal coatings: Fe49.7Cr18Mn1.9Mo7.4W1.6B15.2C3.8Si2.4 Cambridge University Press. 22, (2007).

[17] Y. Wang et al., Electrochemical behaviour of Fe-based metallic glasses in acidic and neutral solutions. Corrosion Science 63, 159-173 (2012).

[18] C. Zhang, K. C. Chan, Y. Wu, L. Liu, Pitting initiation in Fe-based amorphous coatings. Acta Materialia 60, 4152-4159 (2012).

[19] J. Wu, S. D. Zhang, W. H. Sun, Y. Gao, J. Q. Wang, Enhanced corrosion resistance in Fe-based amorphous coatings through eliminating Cr-depleted zones. Corrosion Science 136, 161-173 (2018).

\section{Captions List}

Fig. 1 (a) The XRD Spectra: (a) mixed powders; (b) amorphous composite coatings

Fig. 2 SEM images of (a) as-sprayed surface and (b) cross-section of amorphous coating

Fig. 3 Potentiodynamic polarization curves of different samples in different corrosive solutions: (a) 3.5 wt. $\% \mathrm{NaCl}$; (b) $0.5 \mathrm{M} \mathrm{H}_{2} \mathrm{SO}_{4}$; (c) 10 wt. $\% \mathrm{NaOH}$

Table 1 Summary of the electrochemical parameters of each coating obtained from potentiodynamic polarization curves compared with $316 \mathrm{~L}$

Fig. 4 SEM images of potentiodynamic polarization of different samples in $3.5 \mathrm{wt} . \%$ $\mathrm{NaCl}$ solution:

(a) Fe-based amorphous coating; (b) 15 wt.\%AT13 composite coating; (c) 316L

Fig. 5 SEM images of potentiodynamic polarization of different samples in $0.5 \mathrm{M}$ $\mathrm{H}_{2} \mathrm{SO}_{4}$ solution: (a) Fe-based amorphous coating; (b) 15 wt.\%AT13 composite coating; (c) 316L

Fig. 6 SEM images of potentiodynamic polarization of different samples in 

10wt.\%NaOH solution:(a) Fe-based amorphous coating; (b) 15 wt.\%AT13 composite coating; (c) 316L

Fig. 7 EIS plots of pure Fe-based coating, 5 wt.\%,10 wt.\%,15 wt.\% and 20 wt.\%AT13 composite coatings cafter different immersion times:(a)(c)(e)(g)(i) Nyquist plots; (b)(d)(f)(h)(j) Bode phase plots

Fig. 8 The fitted equivalent circuits: (a) initial stage corrosion of 15 wt. $\%$ and 20 wt.\% AT13 composite coatings; (b) Fe-based coating, 5 wt.\%, 10 wt.\%AT13 composite coatings and later stage corrosion of 15 wt.\% and 20 wt.\% AT13 composite coatings

Fig. 9 The variation of electrochemical parameters for EIS spectra of coating with corrosion time: (a) $\mathrm{R}_{\mathrm{p}}$-Time curve; (b) CPE-c-Time curve; (c) $\mathrm{R}_{\mathrm{ct}}$-Time curve; (d) CPE-ct-Time curve

Fig. 10 XPS spectrum: (a)(c)(e) amorphous coating; (b)(d)(f)(g) 15 wt.\%AT13 composite coating

Fig. 11 Cationic fractions of the oxide species and atomic fractions of the metallic species for the detected $\mathrm{Fe}, \mathrm{Cr}$ and Mo elements by XPS from different coatings

Fig. 12 Corrosion morphology after immersion in 3.5 wt. $\% \mathrm{NaCl}$ solution for 28 days: (a) pure Fe-based coating; (b) 15 wt.\% AT13 composite coating

Fig. 13 The long-term corrosion mechanism diagram of pure Fe-based amorphous coating and composite coating: (a)(b) schematic diagram of coatings; (c)(d) initial stages of corrosion; (e)(f) late stages of corrosion 